\title{
STUDI PEMBAKARAN SPONTAN BATUBARA MENGGUNAKAN METODE PEMANASAN ADIABATIK PADA SKALA LABORATORIUM
}

\author{
Study of Spontaneous Combustion of Coal Using Adiabatic Heating \\ Method on a Laboratory Scale
}

\author{
NUHINDRO P. WIDODO ${ }^{1}$, EDO SYAWALUDIN² dan ZAENAL ARIFIN ${ }^{3}$ \\ ${ }^{1}$ Kelompok Keahlian Teknik Pertambangan, Institut Teknologi Bandung, \\ Jalan Ganesha No. 10 Bandung 40132 \\ e-mail: agungdodo94@gmail.com \\ ${ }^{2}$ Bidang Perencanaan dan Pengendalian Produksi, PT. Timah Tbk. \\ Jalan Jenderal Sudirman 51, Pangkal Pinang 33121, Bangka \\ ${ }^{3}$ PT. Pamapersada Nusantara \\ Jalan Rawagelam I No.9, Kawasan Industri Pulogadung, Jakarta 13930
}

\begin{abstract}
ABSTRAK
Untuk mengatasi kejadian pembakaran spontan batubara yang merugikan, dibutuhkan suatu metode yang dapat mengenali potensi pembakaran spontan batubara. Pada penelitian ini Metode Oksidasi Adiabatik dipelajari untuk menggambarkan proses reaksi oksidasi batubara pada suhu 40-70 ${ }^{\circ} \mathrm{C}$. Percontoh yang digunakan adalah batubara high-volatile C bituminous. Parameter yang diamati adalah ukuran butir, debit suplai oksigen (pada $100 \% \mathrm{O}_{2}$ ) dan kompaksi. Satu buah percontoh memiliki berat 220 gram. Sebanyak 24 percontoh batubara di uji dengan alat pemanas oksidasi adiabatik dan dicatat temperaturnya selama waktu pengujian. Dari hasil penelitian terlihat bahwa nilai laju pembakaran spontan $\left(R_{70}\right)$ terbesar adalah $13,2719{ }^{\circ} \mathrm{C} / \mathrm{jam}$ pada perontoh dengan ukuran 10-14 mesh $(1,410 \mathrm{~mm})$ tanpa kompaksi dengan debit oksigen 0,1 L/menit. Pada percontoh dengan ukuran 170-200 mesh $(0,081 \mathrm{~mm})$ tanpa kompaksi dengan debit oksigen 0,05 L/menit, nilai laju pembakaran spontan $\left(R_{70}\right)$ terbesar adalah $14,75^{\circ} \mathrm{C} /$ jam. Selain itu, nilai energi aktivasi pada kedua percontoh tersebut merupakan yang terendah pada masing-masing kelompok pengujian, yaitu 13,10 kJ/mol dan 11,22 $\mathrm{kJ} / \mathrm{mol}$. Semakin kecil ukuran butir dan pada kondisi tanpa kompaksi, semakin meningkat nilai indeks R70 dan semakin mudah batubara terbakar. Dari kedua pengujian terlihat bahwa ukuran butir dan kompaksi memiliki pengaruh besar terhadap terjadinya pembakaran spontan batubara. Pengaruh debit oksigen tidak memperlihatkan kecenderungan (korelasi) pada kedua pengujian.
\end{abstract}

Kata kunci: pembakaran spontan, batubara, adiabatik, energi aktivasi.

\begin{abstract}
To overcome the adverse event of coal spontaneous combustion, a method is needed to recognize the potential of spontaneous combustion. In this research, the adiabatic oxidation method is studied to describe the process of coal oxidation reaction at $40-70{ }^{\circ} \mathrm{C}$. The sample used in this study was a high-volatile $\mathrm{C}$ bituminous coal. The observed parameters were grain size, oxygen supply discharge (at 100\% $\mathrm{O}_{2}$ ) and compaction. The sample weight was 220 grams. Total of 24 coal samples were tested with adiabatic oxidation oven and temperature of sample was recorded during the test. The study results show that the value of the biggest spontaneous combustion rate $\left(R_{70}\right)$ was $13.2719{ }^{\circ} \mathrm{C} /$ hour for samples of $10-14$ mesh $(1.410 \mathrm{~mm})$ in size without compaction with the oxygen discharge of $0.1 \mathrm{~L} / \mathrm{min}$. The samples with 170-200 mesh in size without compaction with 0.05 $\mathrm{L} / \mathrm{min}$ of oxygen discharge, the largest spontaneous combustion rate (R70) value was $14.75{ }^{\circ} \mathrm{C} /$ hour. In addition,
\end{abstract}


the activation energy in the two samples were the lowest for each test group, namely $13.10 \mathrm{~kJ} / \mathrm{ml}$ and $11.22 \mathrm{~kJ} / \mathrm{mol}$. At the smaller grain size at condition without compaction, the more $R_{70}$ index increased and the easier the coal combusted. Of the two tests, it can be seen that the grain size and compaction had a major influence on the occurrence of coal combustion. The effect of oxygen discharge did not show a trend (correlation) in the tests.

Keywords: spontaneous combustion, coal, adiabatic, activation energy.

\section{PENDAHULUAN}

Hampir semua jenis batubara dapat terbakar secara spontan dalam kondisi lingkungan yang sesuai. Batubara yang terbakar pada tempat penimbunan batubara akan menyebabkan tidak dapat dipasarkannya batubara tersebut. Selain masalah ekonomi, proses pembakaran spontan (spontaneous combustion) juga dapat mengancam keselamatan dan kesehatan para pekerja dekat penimbunan batubara karena batubara yang telah terbakar apabila masuk ke dalam terowongan di bawah penimbunan batubara (reclaim tunnel) memicu terjadinya ledakan jika di dalam terowongan tersebut terdapat metana ataupun debu batubara yang mudah meledak pada konsentrasi tertentu (Widodo, Sulistianto dan Ihsan, 2018). Dengan mempertimbangkan kerugian yang diakibatkan oleh adanya pembakaran spontan batubara, dipandang perlu untuk mengukur secara kuantitatif kecenderungan pembakaran spontan batubara serta faktor-faktor yang memengaruhinya.

Proses pembakaran spontan termasuk reaksi eksotermik. Reaksi oksidasi dari materi karbon adalah faktor utama pada inisiasi pembakaran spontan batubara. Mekanisme pembakaran spontan batubara disebabkan oleh berbagai macam faktor. Secara umum, faktor pemicu pembakaran spontan batubara dibagi dua, yaitu intrinsik dan ekstrinsik. Faktor intrinsik berasal dari batubara itu sendiri, seperti kandungan mineral pirit, kelembaban, peringkat, ukuran partikel, luas permukaan dan lain-lain. Faktor ekstrinsik berasal dari lingkungan seperti suhu, kelembaban udara, tekanan barometrik, konsentrasi oksigen, bakteri dan lain-lain (Cliff, Brady dan Watkinson, 2014; Sloss, 2015).

Metode untuk memperkirakan pembakaran spontan batubara berbeda-beda (Nalbandian, 2010; Sloss, 2015), di antaranya adalah dengan Model Matematika (Aristien dan Widodo, 2015), Thermogravimetric Analysis (TGA) dan Infrared/Fourier Transform Infrared (FTIR) (Zhang dkk., 2015), Crossing Point
Temperature, dan Metode Oksidasi Adiabatik (Beamish dan Beamish, 2011; Beamish dkk., 2013). Pengembangan Metode Oksidasi Adiabatik di Indonesia untuk skala pengujian besar telah dilakukan oleh Pamungkas $d k k$. (2014).

Nilai yang diperoleh dari Metode Adiabatik atau Metode Oksidasi Adiabatik dinyatakan dalam indeks yang dikenal dengan nama R70 indeks. Indeks tersebut didapat dari nilai kemiringan bagian linier kurva pembakaran spontan adiabatik $\left(40-70 \quad{ }^{\circ} \mathrm{C}\right)$. Risiko pembakaran spontan batubara R70 dikaitkan dengan kondisi batubara Queensland diklasifikasikan sebagai berikut (Beamish, Edwards dan Theiler, 2018; Saffari, Ataei dan Sereshki, 2019): nilai $\mathrm{R}_{70}<0,5$ ${ }^{\circ} \mathrm{C} /$ jam dianggap mempunyai risiko kecil (low), $0,5 \leq \mathrm{R}_{70}<1,024^{\circ} \mathrm{C} /$ jam dianggap mempunyai risiko kecil sampai menengah (low-medium), $1,0 \leq R_{70}<2,0{ }^{\circ} \mathrm{C} /$ jam dianggap mempunyai risiko medium (medium), 2,0 $\leq R_{70}<4,0$ ${ }^{\circ} \mathrm{C} /$ jam dianggap mempunyai risiko tinggi (high), 4,0 $\leq \mathrm{R}_{70}<8,0{ }^{\circ} \mathrm{C} / \mathrm{jam}$ dianggap mempunyai risiko sangat tinggi (very high), 8,0 $\leq \mathrm{R}_{70}<16,0{ }^{\circ} \mathrm{C} /$ jam dianggap mempunyai risiko ultra tinggi (ultra high), dan $R_{70} \geq 16,0$ ${ }^{\circ} \mathrm{C} /$ jam dianggap mempunyai risiko ekstrim tinggi (extrimly high).

Selain nilai indeks R70, Metode Oksidasi Adiabatik dapat digunakan untuk mendapatkan nilai energi aktivasi dan faktor pre-eksponensial. Metode oksidasi adibatik dikembangkan oleh Beamish dan digunakan oleh Australian Coal Industry Research Laboratories (ACIRL) sebagai jasa berbayar untuk industri pertambangan batubara.

Penelitian ini membahas pembakaran spontan batubara dengan Metode Oksidasi Adiabatik. Parameter yang digunakan adalah pengaruh ukuran butir batubara, kompaksi batubara, dan debit suplai oksigen terhadap pembakaran spontan batubara high-volatile C bituminous. Faktir ukuran butir termasuk faktor intrinsik, sedangkan faktor kompaksi dan suplai oksigen adalah faktor ekstrinsik. Percontoh diuji 
dengan alat uji oksidasi adiabatik berupa oven pemanas yang suhu ovennya dikontrol oleh alat kontrol temperatur (heater control). Kenaikan temperatur percontoh batubara dicatat selama waktu pengujian.

\section{METODE}

\section{Proses Adiabatik}

Proses adiabatik adalah proses oksidasi yang mempunyai sifat tidak ada pertukaran kalor antara sistem dengan lingkungan. Pada penimbunan batubara, ditemukan hotspot yang terbentuk di tumpukan batubara dan berada pada kondisi mendekati adiabatik.

Dalam pengujian laboratorium ini, agar proses berlangsung secara adiabatik, dilakukan dua cara, yaitu: 1) pembakaran spontan batubara dalam wadah yang diisolasi dengan baik sehingga hanya sedikit kalor yang dapat melewati lapisan batas sistem (dalam pengujian ini yang dimaksud dengan batas sistem adalah wadah percontoh pembakaran spontan batubara), dan 2) menyamakan temperatur lingkungan dengan sistem (dalam pengujian ini yang dimaksud dengan lingkungan adalah temperatur oven), sehingga tidak ada transfer kalor yang terjadi (Moran $d k k ., 2018$ ).

Dengan proses adiabatik, maka kalor yang terjadi dari reaksi pembakaran spontan batubara akan digunakan kembali ke dalam sistem untuk reaksi pembakaran berikutnya.

Metode oksidasi adiabatik adalah metode yang banyak digunakan di berbagai negara, khususnya Australia. Hal ini dikarenakan pengujian oksidasi adiabatik dianggap sebagai pendekatan terbaik untuk simulasi kondisi tambang, khususnya proses oksidasi pada tumpukan batubara. Pengujian adiabatik telah banyak dilakukan untuk menentukan kecenderungan dari batubara untuk mengalami proses pembakaran spontan (Beamish dkk., 2013; Beamish, Edwards dan Theiler, 2018; Saffari, Ataei dan Sereshki, 2019).

Penelitian sebelumnya yang dilakukan oleh Beamish dan Beamish (2010, 2011) mempelajari pengaruh dari faktor ukuran butir, kandungan kelembaban dan persentase oksigen. Pengujian ini mencoba untuk meneliti faktor yang lain, yaitu kombinasi perubahan debit aliran oksigen dan kompaksi.

\section{Kecenderungan Pembakaran Spontan Batubara}

Dalam penelitian ini, parameter yang digunakan untuk melihat karakteristik pembakaran spontan batubara adalah nilai pemanasan mandiri atau yang disebut $\mathrm{R}_{70}$ yang dirumuskan pada Persamaan 1 (Beamish dan Beamish, 2010), sebagai berikut:

$\mathrm{R}_{70}=\left(70-40{ }^{\circ} \mathrm{C}\right) / \Delta t 40-70$

Nilai $\Delta t_{40-70}$ adalah waktu yang dibutuhkan oleh proses oksidasi percontoh batubara untuk meningkatkan temperatur percontoh dari $40^{\circ} \mathrm{C}$ sampai $70{ }^{\circ} \mathrm{C}$.

\section{Parameter Kinetik Oksidasi}

Proses pembakaran spontan batubara termasuk dalam reaksi eksotermik. Hal ini dapat dilihat pada kenaikan temperatur percontoh batubara. Tetapi reaksi eksotermis tidak dapat dipertahankan karena adanya perpindahan panas melalui konduksi. Keadaan ini digambarkan oleh persamaan keseimbangan panas (Zhang $d k k ., 2013)$ pada Persamaan 2, sebagai berikut:

$q=\rho c[d T / d t]=Q \rho A \exp (-E / R T)$

\section{Keterangan:}

$\mathrm{q}$ = laju pemanasan sendiri batubara

$\mathrm{C}=$ kapasitas panas batubara $(\mathrm{J} / \mathrm{kg} \mathrm{K})$

$\rho=$ densitas batubara $\left(\mathrm{kg} / \mathrm{m}^{3}\right)$

$\mathrm{T}=$ temperatur percontoh $(\mathrm{K})$

$\mathrm{t}=$ waktu (s)

$\mathrm{Q}=$ panas reaksi $(\mathrm{J} / \mathrm{kg})$

$\mathrm{A}=$ faktor pre-eksponensial $\left(\mathrm{s}^{-1}\right)$

$\mathrm{E}=$ energi aktivasi $(\mathrm{J} / \mathrm{mol})$

$\mathrm{R}=$ konstanta molar gas $=8,314 \mathrm{~kJ} / \mathrm{mol} \mathrm{K}$

Ketika keadaan adiabatik tercapai dan kecepatan aliran menuju bawah tumpukan batubara diabaikan, panas yang hilang melalui konduksi dapat diabaikan sehingga persamaan dapat disederhanakan menyerupai persamaan Arrhenius. Nilai energi aktivasi (E) dan hasil perkalian panas dari reaksi dengan faktor preeksponensial (QA) dapat ditentukan dari Persamaan 3 (Sasaki $d k k ., 2014$ ), sebagai berikut:

$\ln [\mathrm{d} T / \mathrm{dt}]=\ln (\mathrm{QA} / \mathrm{c})-(\mathrm{E} / \mathrm{RT})$ 


\section{PENGUJIAN OKSIDASI ADIABATIK}

Parameter pertama yang akan dipelajari dalam pengujian ini adalah besar butir batubara, yaitu batubara yang lolos ayakan 3-4 mesh $(5,690$ $\mathrm{mm}), 6-8$ mesh $(2,845 \mathrm{~mm}), 10-14$ mesh $(1,410$ $\mathrm{mm}), 60-80$ mesh $(0,213 \mathrm{~mm}), 100-140$ mesh $(0,126 \mathrm{~mm})$ dan 170-200 mesh $(0,081 \mathrm{~mm})$. Proses ini dilakukan dengan sieve shaker. Setiap percontoh yang diuji memiliki berat sekitar 220 gram.

Parameter kedua yang dipelajari dalam penelitian ini adalah faktor kompaksi batubara yang didasarkan kepada nilai tekanan yang terjadi pada tumpukan batubara oleh bulldozer dan umumnya berada di tempat penimbunan batubara (Komatsu D65 PX 16). Tekanan yang digunakan dalam penelitian ini bervariasi mulai dari kondisi tanpa tekanan, kemudian dengan tekanan 10, 17,2 dan 34,3 kPa.

Parameter ketiga yang dipelajari adalah debit oksigen, untuk melihat pengaruh posisi batubara pada penimbunan batubara. Pada posisi yang dekat dengan permukaan penimbunan, batubara akan mendapat aliran oksigen lebih besar daripada yang berada relatif lebih jauh dari permukaan penimbunan. Adapun variasi debit oksigen yang digunakan adalah 0,05, 0,1 dan 0,2 L/menit.

Ketiga parameter tersebut dipilih karena merupakan faktor yang terlihat secara eksplisit dan dapat dikontrol langsung di lapangan. Berbeda dengan faktor intrinsik yang lain, seperti kandungan sulfur, yang sangat sulit untuk dikontrol pada skala lapangan.

\section{Preparasi Percontoh Batubara}

Data karakteristik percontoh batubara dapat dilihat pada Tabel 1. Batubara tersebut mempunyai nilai kalori $4525 \mathrm{kal} / \mathrm{g}$ (adb) dengan kadar air 25,41\% (adb), kadar abu $5,74 \%$ (adb) dan sulfur 1,51\% (adb), dengan konversi, percontoh mempunyai nilai kalori setara dengan 28021 (dmmf) dan tergolong dalam batubara dengan klasifikasi high-volatile C bituminous menurut ASTM D388-15 (2017).

Tahapan yang dilakukan untuk preparasi percontoh batubara adalah tahap kominusi (reduksi ukuran butir) dengan proses crushing, grinding dan sieving. Setelah itu, dilakukan conning quartering untuk homogenisasi dan membagi percontoh.

Tabel 1. Karakteristik batubara penelitian

\begin{tabular}{lccc}
\hline \multicolumn{1}{c}{ Parameter Analisis } & Nilai & Unit & Basis \\
\hline Kadar Air & 25,41 & $\%$ & $\mathrm{adb}$ \\
Kadar Abu & 5,74 & $\%$ & $\mathrm{adb}$ \\
Kadar Zat Menguap & 35,75 & $\%$ & $\mathrm{adb}$ \\
Kadar Karbon Terikat & 33,1 & $\%$ & $\mathrm{adb}$ \\
Sulfur & 1,51 & $\%$ & $\mathrm{adb}$ \\
Nilai Kalori Kotor & 4525 & $\mathrm{kal} / \mathrm{g}$ & $\mathrm{adb}$ \\
\hline
\end{tabular}

\section{Proses Pengujian dengan Oven Adiabatik}

Alat oksidasi adiabatik terdiri dari tiga bagian, yaitu oven, wadah percontoh, dan heater control (Gambar 1). Oven mempunyai daya 1000 W dengan lapisan glass wool sebagai insulator panas. Selain itu oven juga dilengkapi dengan exhaust fan untuk mendistribusikan panas. Batubara pada uji pembakaran spontan ditempatkan dalam wadah percontoh dengan bahan aluminium yang mempunyai insulator (Gambar 2) dengan volume wadah percontoh sebesar $350 \mathrm{ml}$. Adapun pipa tembaga yang mengalirkan oksigen ke dalam wadah percontoh dipasang di dalam oven (di sekeliling wadah percontoh) untuk memastikan temperatur udara/ oksigen suplai sama dengan temperatur oven ketika mencapai wadah percontoh (Gambar 2).

Pengujian awal temperatur kamar menunjukkan umumnya temperatur oven adiabatik sedikit di atas temperatur wadah percontoh karena sistem penyalaan pemanas dengan solid state relay. Sistem pengontrol pemanas dengan solid state relay mempunyai sifat seperti saklar untuk memutus dan menyambungkan aliran listrik ke pemanas karena pemanas yang digunakan mempunyai daya 1000 watt sehingga menimbulkan lonjakan panas yang tinggi di fase awal. Hal ini tidak menjadi masalah karena proses pengujian dimulai ketika temperatur $40{ }^{\circ} \mathrm{C}$ sampai batubara terbakar. Pada rentang temperatur tersebut, perbedaan temperatur oven dan percontoh sudah semakin rendah (2 sampai $4{ }^{\circ} \mathrm{C}$ ) dan percontoh berada pada wadah dengan insulator sehingga keadaan mendekati adiabatik tercapai. 


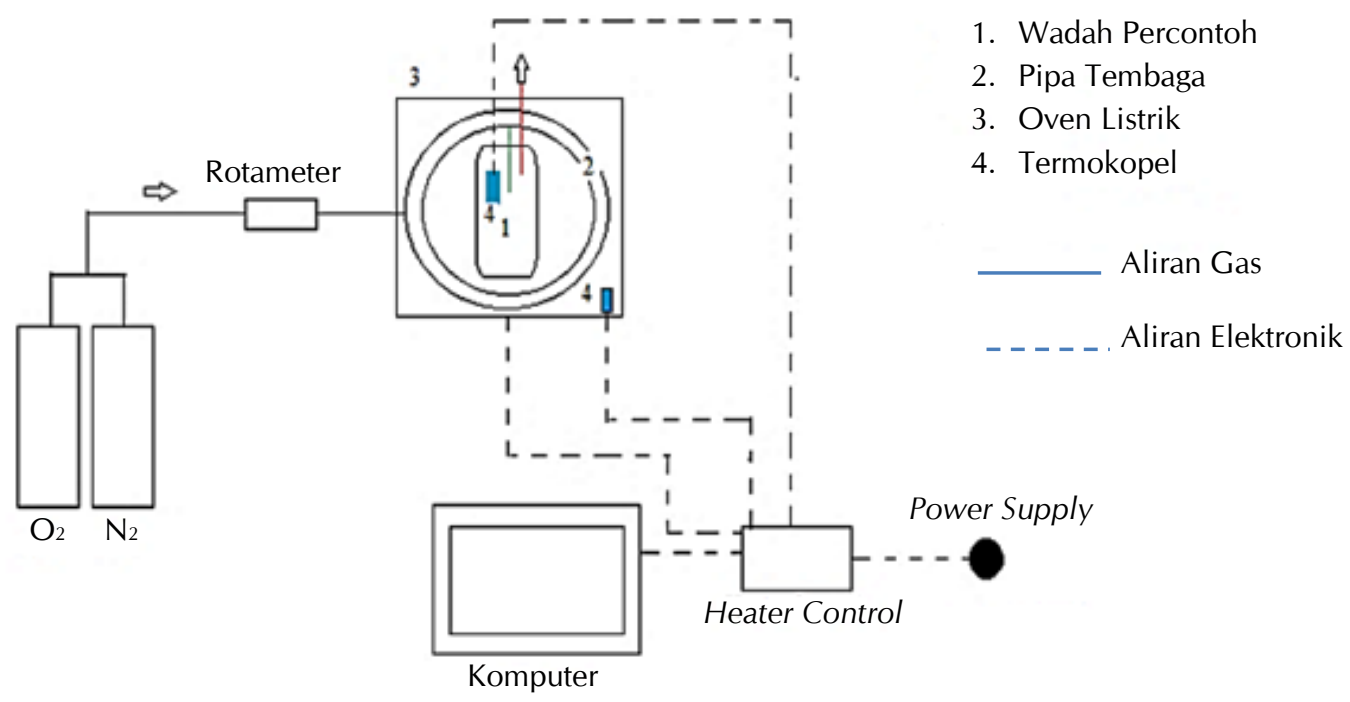

Gambar 1. Skema alat uji oksidasi adiabatik

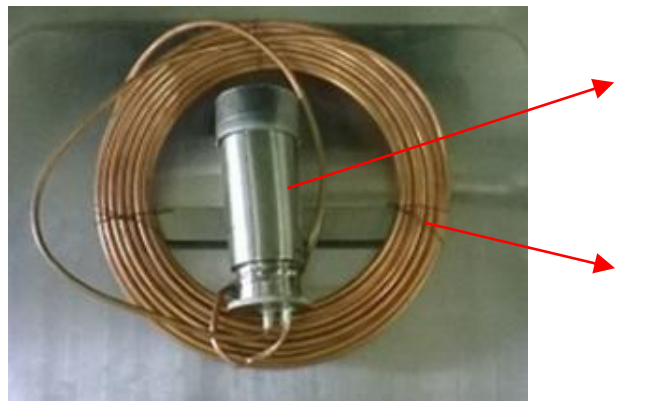

Wadah percontoh batubara

Gambar 2. Wadah percontoh batubara dan pipa tembaga

Heater control yang terdiri dari rangkaian elektronik berfungsi untuk mengatur suhu oven dan menyimpan data pengukuran temperatur percontoh maupun oven. Dua buah termokopel digunakan sebagai sensor temperatur oven dan percontoh.

Prosedur pengujian oksidasi adiabatik dibagi menjadi dua tahap yaitu proses pengeringan dan pemanasan batubara. Proses pengeringan dilakukan selama 12 jam pada temperatur 120 ${ }^{\circ} \mathrm{C}$ sambil dialirkan gas nitrogen dengan debit $0,1 \mathrm{~L} / \mathrm{menit}$ (Catatan: lama pengeringan yang dilakukan relatif berbeda dengan standar yang dilakukan Beamish dan Beamish (2011), yaitu 16 jam pada temperature $110{ }^{\circ} \mathrm{C}$. Hal ini dipertimbangkan karena kondisi temperatur pengujian yang relatif lebih tinggi yaitu 120 $\left.{ }^{\circ} \mathrm{C}\right)$. Proses pengeringan dilakukan untuk menghilangkan Free Moisture (FM) percontoh batubara. Setelah proses pengeringan selesai, oven adiabatik dimatikan supaya temperatur percontoh di dalam wadah menurun sampai temperatur ruang. Kemudian, pengontrol pemanas yang digunakan untuk proses pengeringan (solid state relay) akan diganti dengan pengontrol pemanas (heater control) yang terbuat dari mikrokontroler atmel untuk proses pemanasan. Proses pemanasan dimulai pada temperatur ruang sampai $40{ }^{\circ} \mathrm{C}$ sambil dialirkan gas nitrogen dengan debit 0,1 $\mathrm{L} /$ menit. Setelah mencapai $40^{\circ} \mathrm{C}$, gas oksigen akan dialirkan dengan variasi debit alir yang diinginkan untuk menggantikan gas nitrogen. Datalogger akan menyimpan data temperatur percontoh dan oven terhadap waktu. Pengujian dilakukan sampai percontoh terbakar. Ketika percontoh batubara mencapai temperatur $120-140{ }^{\circ} \mathrm{C}$ akan mengalami keadaan take off, suatu keadaan yang menunjukkan kenaikan temperatur batubara tidak dapat diimbangi oleh oven adiabatik yang diatur oleh heater control. 


\section{HASIL DAN PEMBAHASAN}

\section{Indeks Kecenderungan Pembakaran Spontan Batubara}

Pada penelitian ini rentang temperatur yang diamati serupa dengan metode Beamish dan Beamish $(2010,2011)$ yaitu antara $40-70{ }^{\circ} \mathrm{C}$ karena pada rentang tersebut mempunyai laju pemanasan yang relatif linier. Regresi kurva pemanasan batubara terjadi antara $40-70{ }^{\circ} \mathrm{C}$ dan menghasilkan persamaan linier $y=10,27$ $x+40$ (Gambar 3). Dengan nilai tersebut didapat nilai R 70 sebesar $10,27{ }^{\circ} \mathrm{C} / \mathrm{jam}$, yang berarti mempunyai risiko ultra tinggi mengalami proses pembakaran spontan (nilai 8,0 $\leq R_{70}<$ $16,0^{\circ} \mathrm{C} /$ jam dianggap mempunyai risiko ultra tinggi (ultra high).

Nilai kecenderungan pembakaran spontan pada penelitian ini dapat dilihat pada Tabel 2 . Secara umum terlihat bahwa batubara yang diuji memiliki nilai R7o di atas 3,6 hingga 13,9 ${ }^{\circ} \mathrm{C} / \mathrm{jam}$, yang berarti berarti mempunyai risiko tinggi (high) hingga ultra tinggi (ultra high) mengalami proses pembakaran spontan.

Plot hasil nilai R7o pada penelitian ini terhadap diameter rata-rata batubara untuk berbagai kondisi pemadatan butiran dan berbagai kondisi debit oksigen dapat dilihat pada Gambar 4.

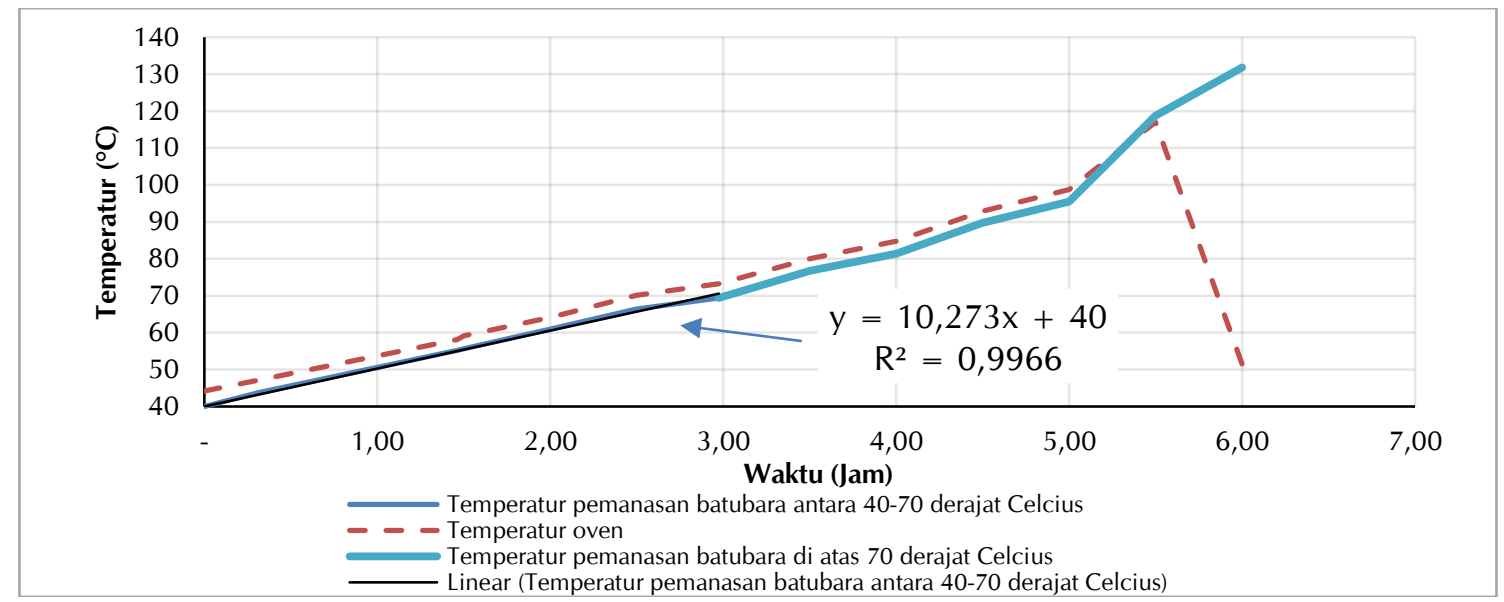

Gambar 3. Kurva kenaikan temperatur percontoh dan oven adiabatik untuk pengujian pemanasan spontan batubara pada ukuran butir rata-rata 0,213 mm (60-80 mesh) dengan debit oksigen 0,05 L/menit

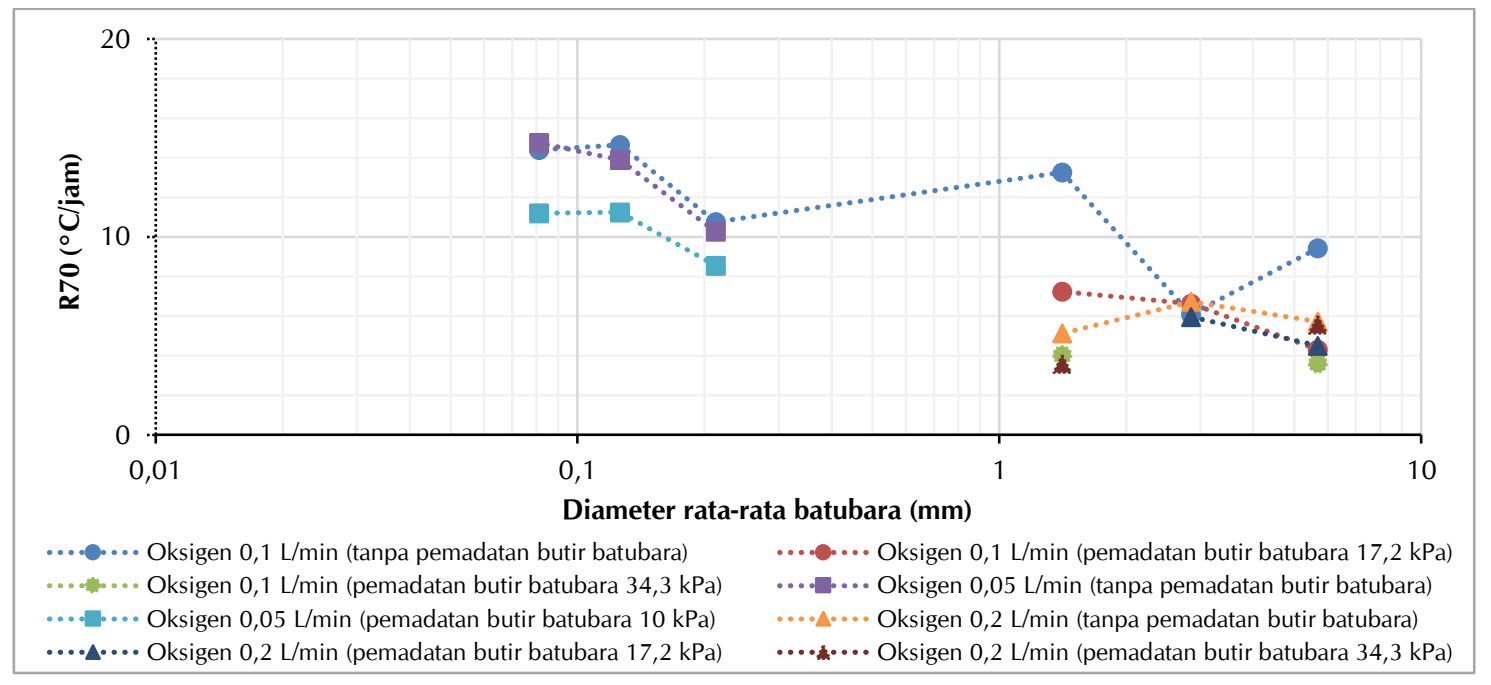

Gambar 4. Plot hasil nilai R7o terhadap diameter rata-rata batubara untuk berbagai kondisi pemadatan butiran dan berbagai kondisi debit oksigen 
Tabel 2. Nilai R7o Pengujian

\begin{tabular}{|c|c|c|c|c|c|c|c|c|}
\hline \multirow{2}{*}{$\begin{array}{c}\text { Debit } \\
\text { Oksigen } \\
\text { (L/menit) }\end{array}$} & \multirow{2}{*}{$\begin{array}{l}\text { Diameter } \\
\text { butir } \\
\text { batubara } \\
\text { maksimun } \\
(\mathrm{mm})\end{array}$} & \multirow{2}{*}{$\begin{array}{l}\text { Diameter } \\
\text { butir } \\
\text { batubara } \\
\text { minimun } \\
\text { (mm) }\end{array}$} & \multirow{2}{*}{$\begin{array}{l}\text { Diameter } \\
\text { butir } \\
\text { batubara } \\
\text { rata-rata } \\
(\mathrm{mm})\end{array}$} & \multirow{2}{*}{$\begin{array}{l}\text { Ukuran } \\
\text { ayakan } \\
\text { (mesh) }\end{array}$} & \multicolumn{4}{|c|}{$\begin{array}{c}\mathrm{R}_{70}\left({ }^{\circ} \mathrm{C} / \mathrm{jam}\right) \text { pada berbagai tingkat } \\
\text { pemadatan butir batubara }\end{array}$} \\
\hline & & & & & $0 \mathrm{kPa}$ & $10 \mathrm{kPa}$ & $17,2 \mathrm{kPa}$ & $34,3 \mathrm{kPa}$ \\
\hline \multirow{3}{*}{0,2} & 6,68 & 4,699 & 5,690 & $3-4$ & 5,736 & TU & 4,509 & 5,579 \\
\hline & 3,327 & 2,362 & 2,845 & $6-8$ & 6,729 & TU & 5,965 & TU \\
\hline & 1,651 & 1,168 & 1,410 & $10-14$ & 5,131 & TU & TU & 3,594 \\
\hline \multirow{6}{*}{0,1} & 6,68 & 4,699 & 5,690 & $3-4$ & 9,432 & TU & 4,317 & 3,613 \\
\hline & 3,327 & 2,362 & 2,845 & $6-8$ & 6,091 & TU & 6,626 & TU \\
\hline & 1,651 & 1,168 & 1,410 & $10-14$ & 13,272 & TU & 7,238 & 4,047 \\
\hline & 0,25 & 0,175 & 0,213 & $60-80$ & 10,76 & TU & TU & TU \\
\hline & 0,147 & 0,105 & 0,126 & $100-140$ & 14,65 & TU & TU & TU \\
\hline & 0,088 & 0,074 & 0,081 & $170-200$ & 14,4 & TU & TU & TU \\
\hline \multirow{3}{*}{0,05} & 0,25 & 0,175 & 0,213 & $60-80$ & 10,27 & 8,555 & TU & TU \\
\hline & 0,147 & 0,105 & 0,126 & $100-140$ & 13,89 & 11,25 & TU & TU \\
\hline & 0,088 & 0,074 & 0,081 & $170-200$ & 14,75 & 11,21 & TU & TU \\
\hline
\end{tabular}

Keterangan:

1. TU: Tidak Diuji. Hal ini dikarenakan adanya keterbatasan waktu pengujian, dan penelitian ini adalah penelitian awal.

2. Pengujian standar pada kondisi $0 \mathrm{kPa}$ (percontoh tidak dipadatkan) dilakukan untuk semua percontoh, sesuai dengan standar pengujian yang dilakukan oleh Beamish dan Beamish $(2010,2011)$.

3. Pemilihan variable yang diuji berdasarkan pada pengalaman lapangan, yaitu kondisi di penimbunan batubara yang berbeda (kondisi ruang antar butir batubara dengan pemadatan karena adanya alat berat yaitu dozer) akan berbeda dengan kondisi ruang antar butir batubara tanpa pemadatan. Selain itu dari hasil studi literatur (Aristien dan Widodo, 2015) juga akan ada pengaruh ukuran butir dan posisi percontoh di penimbunan batubara yang memengaruhi laju suplai oksigen, terhadap nilai $\mathrm{R}_{70 .}$

Dari Gambar 4, terlihat kecenderungan pembakaran spontan semakin meningkat dengan semakin kecil ukuran butir (ditunjukkan dengan nilai $R_{70}$ yang semakin besar). Hal ini dikarenakan pada ukuran butir yang lebih luas permukaan efektif semakin besar, sehingga akan mempermudah terjadinya pembakaran spontan.

Untuk pengaruh kompaksi, terlihat kecenderungan bahwa nilai $R_{70}$ mengalami penurunan dengan adanya kompaksi pada hampir semua ukuran butir batubara untuk seluruh debit oksigen. Namun demikian pada ukuran butir batubara yang paling besar yaitu $5,69 \mathrm{~mm}$ untuk debit oksigen yang paling besar $(0,2 \mathrm{~L} /$ menit), pengaruh pemadatan tidak terlihat dengan jelas yang ditunjukkan dengan nilai $R_{70}$ yang meningkat kembali pada pemadatan yang paling besar $(34,3 \mathrm{kPa})$ dibandingkan dengan pemadatan yang lebih kecil $(17,2 \mathrm{kPa})$, yaitu dari 4,509 ${ }^{\circ} \mathrm{C} /$ jam menjadi 5,579 ${ }^{\circ} \mathrm{C} /$ jam. Adanya kemungkinan pecahnya batubara ukuran tersebut serta interaksi oksigen terhadap batubara pada pemadatan $34,3 \mathrm{kPa}$ dapat meningkatkan kembali potensi pembakaran spontan batubara.
Pada ukuran butir batubara yang paling besar (5,69 mm) dengan debit oksigen 0,2 L/menit, pemadatan memberikan efek yang berlawanan dengan hasil yang lainnya, yaitu semakin padat, semakin besar nilai $R_{70}$, yaitu $(4,509$ ${ }^{\circ} \mathrm{C} / j a m$ pada tekanan 17,2 kPa dan 5,579 pada tekanan 34,3 kPa). Hal ini menjadi indikasi bahwa pada ukuran besar, semakin besar tekanan, semakin banyak batubara yang berinteraksi dan dengan adanya rongga akibat ukuran butir yang besar, maka pembakaran spontan menjadi semakin mudah.

\section{Parameter Kinetik Oksidasi}

Laju reaksi antara batubara dan oksigen sangat dipengaruhi oleh dua faktor, yaitu kimia (tipe karbon, kandungan pengotor dalam batubara, dll.) dan karakteristik fisik (luas permukaan, pori dan difusi permukaan). Untuk setiap jenis batubara mempunyai sifat fisik yang berbeda dan mempunyai nilai parameter kinetik oksidasi yang berbeda juga.

Dari Persamaan 2, diketahui bahwa nilai indeks $R_{70}$ (yang pada persamaan tersebut akan sebanding dengan q), mempunyai hubungan langsung dengan energi aktivasi (E). Nilai R70 yang semakin besar menggambarkan batubara 
yang mempunyai energi aktivasi semakin kecil. Hal ini menandakan batubara semakin reaktif. Pada penelitian yang dilakukan oleh Wang dkk. (2019) tidak terdapat hubungan kereaktifan batubara dengan ukuran partikel pada ukuran percontoh 0,5 hingga $10 \mathrm{~mm}$.

Tabel 3 dan Tabel 4 menunjukkan nilai energi aktivasi dan hasil perkalian panas reaksi dengan faktor pre-eksponensial tidak bisa didapatkan pada percontoh ukuran 5,69, 2,845, dan 0,213 mm (pada debit oksigen 0,1 dan 0,2 L/menit.). Hal ini diakibatkan oleh kurva yang tidak memadai untuk perhitungan karena grafik kenaikan temperatur setelah kondisi linear tidak eksponensial.

Tabel 3. Nilai energi aktivasi pengujian

\begin{tabular}{|c|c|c|c|c|c|c|}
\hline \multirow{2}{*}{$\begin{array}{l}\text { Debit Oksigen } \\
\text { (L/menit) }\end{array}$} & \multirow{2}{*}{$\begin{array}{l}\text { Diameter rata-rata } \\
(\mathrm{mm})\end{array}$} & \multirow{2}{*}{$\begin{array}{l}\text { Ukuran ayakan } \\
\text { (mesh) }\end{array}$} & \multicolumn{4}{|c|}{$\begin{array}{c}\text { Energi aktivasi } \mathrm{E}(\mathrm{kJ} / \mathrm{mol}) \text { pada berbagai tingkat } \\
\text { pemadatan butir batubara }\end{array}$} \\
\hline & & & $0 \mathrm{kPa}$ & $10 \mathrm{kPa}$ & $17,2 \mathrm{kPa}$ & $34,3 \mathrm{kPa}$ \\
\hline \multirow{3}{*}{0,2} & 5,690 & $3-4$ & $\mathrm{TDH}$ & TU & $\mathrm{TDH}$ & TDH \\
\hline & 2,845 & $6-8$ & $\mathrm{TDH}$ & TU & $\mathrm{TDH}$ & TU \\
\hline & 1,410 & $10-14$ & 21,38 & TU & TU & $\mathrm{TDH}$ \\
\hline \multirow{6}{*}{0,1} & 5,690 & $3-4$ & $\mathrm{TDH}$ & $\mathrm{TU}$ & $\mathrm{TDH}$ & $\mathrm{TDH}$ \\
\hline & 2,845 & $6-8$ & $\mathrm{TDH}$ & TU & $\mathrm{TDH}$ & TU \\
\hline & 1,410 & $10-14$ & 13,1 & TU & 27,71 & $\mathrm{TDH}$ \\
\hline & 0,213 & $60-80$ & 37,25 & TU & TU & TU \\
\hline & 0,126 & $100-140$ & $\mathrm{TDH}$ & TU & TU & TU \\
\hline & 0,081 & $170-200$ & 28,36 & TU & TU & TU \\
\hline \multirow{3}{*}{0,05} & 0,213 & $60-80$ & 34,48 & 34,27 & TU & TU \\
\hline & 0,126 & $100-140$ & 18,07 & 18,95 & TU & TU \\
\hline & 0,081 & $170-200$ & 11,22 & 14,23 & TU & TU \\
\hline
\end{tabular}

Keterangan:

1. TU : Tidak Diuji. Hal ini dikarenakan adanya keterbatasan waktu pengujian, dan penelitian ini adalah penelitian awal.

2. TDH : Tidak Dapat Dihitung. Hal ini diakibatkan oleh kurva yang tidak memadai untuk perhitungan karena grafik kenaikan temperatur setelah kondisi linear tidak eksponensial.

Tabel 4. Faktor pre-eksponensial pengujian

\begin{tabular}{|c|c|c|c|c|c|c|}
\hline \multirow{2}{*}{$\begin{array}{l}\text { Debit Oksigen } \\
\text { (L/menit) }\end{array}$} & \multirow{2}{*}{$\begin{array}{l}\text { Diameter rata-rata } \\
(\mathrm{mm})\end{array}$} & \multirow{2}{*}{$\begin{array}{l}\text { Ukuran ayakan } \\
\text { (mesh) }\end{array}$} & \multicolumn{4}{|c|}{$\begin{array}{l}\text { Faktor pre-eksponensial QA (kJ/kg s) pada } \\
\text { berbagai tingkat pemadatan butir batubara }\end{array}$} \\
\hline & & & $0 \mathrm{kPa}$ & $10 \mathrm{kPa}$ & $17,2 \mathrm{kPa}$ & $34,3 \mathrm{kPa}$ \\
\hline \multirow{3}{*}{0,2} & 5,690 & $3-4$ & $\mathrm{TDH}$ & TU & $\mathrm{TDH}$ & $\mathrm{TDH}$ \\
\hline & 2,845 & $6-8$ & $\mathrm{TDH}$ & TU & $\mathrm{TDH}$ & TU \\
\hline & 1,410 & $10-14$ & 530,0 & TU & TU & $\mathrm{TDH}$ \\
\hline \multirow{6}{*}{0,1} & 5,690 & $3-4$ & $\mathrm{TDH}$ & TU & $\mathrm{TDH}$ & $\mathrm{TDH}$ \\
\hline & 2,845 & $6-8$ & $\mathrm{TDH}$ & TU & $\mathrm{TDH}$ & TU \\
\hline & 1,410 & $10-14$ & 35,3 & TU & 3500 & $\mathrm{TDH}$ \\
\hline & 0,213 & $60-80$ & 58032,4 & TU & TU & TU \\
\hline & 0,126 & $100-140$ & TDH & TU & TU & TU \\
\hline & 0,081 & $170-200$ & 11681,5 & TU & TU & TU \\
\hline \multirow{3}{*}{0,05} & 0,213 & $60-80$ & 33215,0 & 188,2 & TU & TU \\
\hline & 0,126 & $100-140$ & 272,0 & 188,2 & TU & TU \\
\hline & 0,081 & $170-200$ & 13,3 & 170,8 & TU & TU \\
\hline
\end{tabular}

Keterangan:

1. TU : Tidak Diuji. Hal ini dikarenakan adanya keterbatasan waktu pengujian, dan penelitian ini adalah penelitian awal.

2. TDH : Tidak Dapat Dihitung. Hal ini diakibatkan oleh kurva yang tidak memadai untuk perhitungan karena grafik kenaikan temperatur setelah kondisi linear tidak eksponensial. 


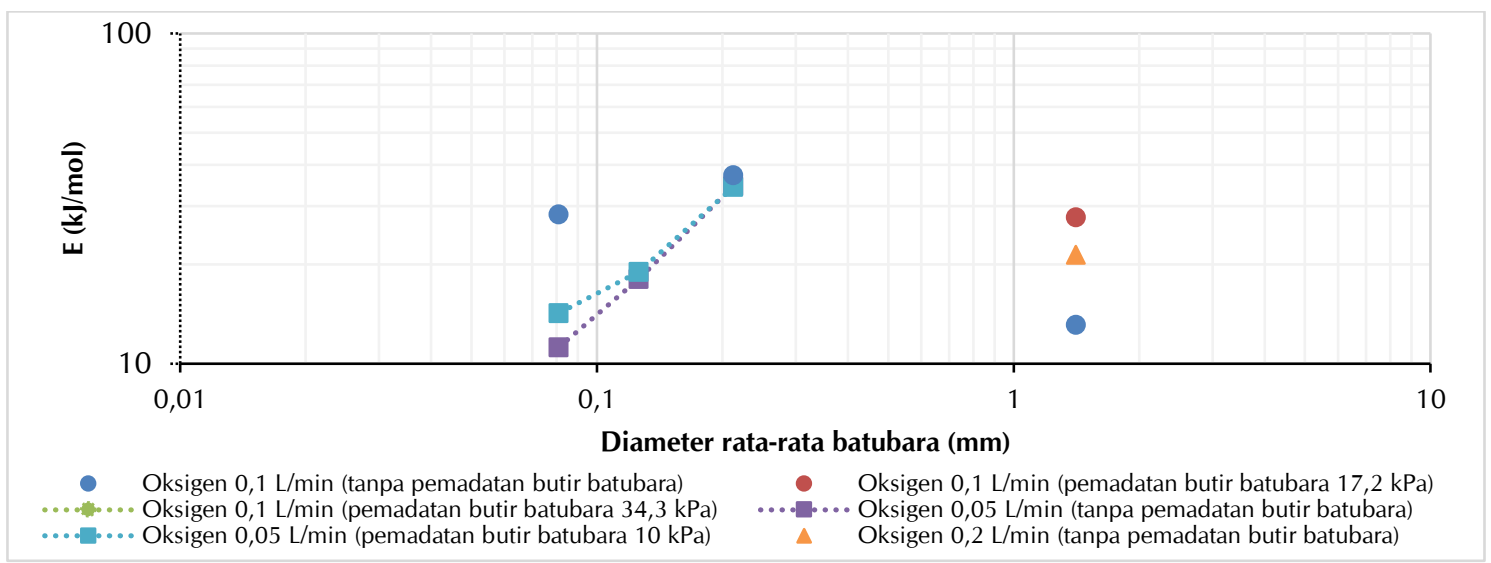

Gambar 5. Plot hasil nilai energi aktivasi terhadap diameter rata-rata batubara untuk berbagai kondisi pemadatan butiran dan berbagai kondisi debit oksigen

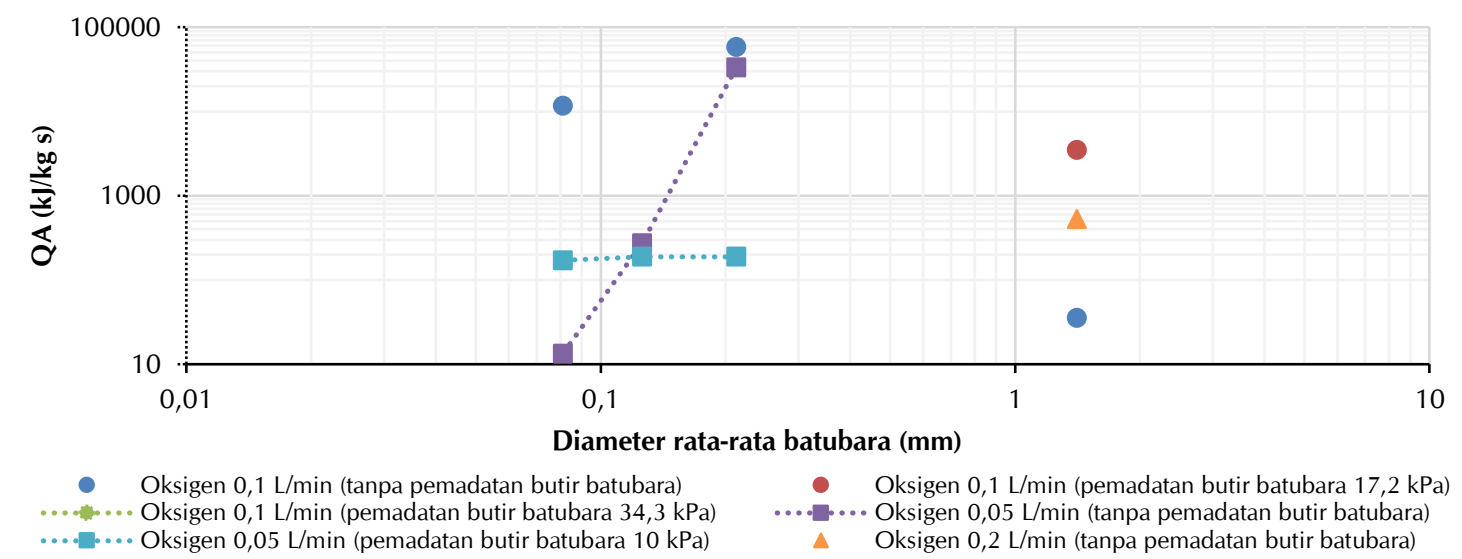

Gambar 6. Plot hasil faktor pre-eksponensial terhadap diameter rata-rata batubara untuk berbagai kondisi pemadatan butiran dan berbagai kondisi debit oksigen

Pada percontoh ukuran $1,41 \mathrm{~mm}$ tanpa kompaksi dengan debit oksigen $0,1 \mathrm{~L} /$ menit memiliki nilai $R_{70}$ sebesar $13,272{ }^{\circ} \mathrm{C} /$ jam menyatakan bahwa percontoh ini memiliki sifat kecenderungan pembakaran spontan paling besar di antara semua percontoh dengan debit oksigen $0,1 \mathrm{~L} /$ menit. Hal tersebut sejalan dengan nilai energi aktivasi yang relatif kecil $(13,1 \mathrm{~kJ} / \mathrm{mol})$. Pada pengujian ini, faktor preeksponensial yang kecil (35,3 kJ/kg s) juga mempunyai peranan terhadap terjadinya proses pembakaran spontan.

Hal tersebut juga terlihat pada pengujian batubara dengan ukuran butir 0,08 $\mathrm{mm}$ tanpa kompaksi dengan udara debit suplai 0,05 L/menit mempunyai $R_{70}$ sebesar 14,750 ${ }^{\circ} \mathrm{C} /$ jam. Percontoh tersebut mempunyai $\mathrm{R}_{70}$ terbesar dari seluruh percontoh pada pengujian kedua. Hal ini sejalan dengan nilai energi aktivasi yang paling rendah $(11,22$ $\mathrm{kJ} / \mathrm{mol}$ ) dari percontoh lain.

Pada keadaan ukuran butir 1,41 mm tanpa kompaksi, debit oksigen 0,2 L/menit mempunyai faktor pre-eksponensial $(530 \mathrm{~kJ} / \mathrm{kg}$ s) dan energi aktivasi $(21,38 \mathrm{~kJ} / \mathrm{mol})$ lebih besar daripada keadaan debit oksigen 0,1 L/menit. Hal ini sejalan dengan nilai $R_{70}$ pada 0,2 L/menit $\left(5,13{ }^{\circ} \mathrm{C} /\right.$ jam $)$ lebih kecil daripada nilainya pada $0,1 \mathrm{~L} /$ menit $\left(13,3{ }^{\circ} \mathrm{C} / \mathrm{jam}\right)$.

Pada keadaan ukuran butir paling kecil, yaitu 0,081 mm dan tanpa kompaksi, debit oksigen $0,1 \mathrm{~L} / \mathrm{menit}$ mempunyai faktor preeksponensial $(11681,5 \mathrm{~kJ} / \mathrm{kg}$ s) dan energi aktivasi $(28,36 \mathrm{~kJ} / \mathrm{mol})$ lebih besar daripada keadaan debit oksigen 0,05 L/menit $(13,3 \mathrm{~kJ} / \mathrm{kg}$ 
dan $11,22 \mathrm{~kJ} / \mathrm{mol}$ ). Namun hal ini tidak sejalan dengan nilai $R_{70}$ hasil pengujian, yaitu pada 0,1 $\mathrm{L} /$ menit mendekati nilai pada $0,05 \mathrm{~L} /$ menit $\left( \pm 14^{\circ} \mathrm{C} / \mathrm{jam}\right)$.

\section{KESIMPULAN}

Berdasarkan hasil eksperimen yang telah dilakukan, dapat ditarik kesimpulan:

- Meningkatnya kecenderungan pembakaran spontan sebanding dengan penurunan ukuran partikel;

- Kecenderungan pembakaran spontan memiliki hubungan berbanding terbalik dengan kompaksi;

- Adanya hubungan antara nilai R70 dengan energi aktivasi dan faktor pre-eksponensial untuk pengujian tanpa kompaksi, yaitu semakin besar nilai $R_{70}$ semakin kecil nilai energi aktivasi dan faktor pre-eksponensial, demikian pula sebaliknya. Namun demikian untuk ukuran paling kecil, yaitu 0,081 mm, hubungan tersebut menjadi tidak sejalan;

- Tidak terdapat hubungan yang jelas antara nilai $R_{70}$ terhadap laju oksigen. Hal ini karena kondisi optimum pembakaran akan menyesuaikan reaksi kimia yang terjadi dan spesifik untuk kondisi tertentu.

\section{UCAPAN TERIMA KASIH}

Penulis mengucapkan terima kasih kepada Program Studi Teknik Pertambangan dan Kelompok Keahlian Teknik Pertambangan, Fakultas Teknik Pertambangan dan Perminyakan, Institut Teknologi Bandung, melalui Program Penelitian, Pengabdian kepada Masyarakat dan Inovasi ITB (P3MI-ITB) yang telah memberikan dukungan dalam pelaksanaan penelitian ini.

\section{DAFTAR PUSTAKA}

Aristien, H. dan Widodo, N. P. (2015) "Modeling of coal temperature distribution to estimate rate of temperature increase on coal stockpile spontaneous combustion using finite difference method," in International Symposium on Earth Science and Technology 2015. Bandung: Institut Teknologi Bandung.
ASTM D388-15 (2017) "Standard classification of coals by rank," in Annual Book of ASTM Standards. 05.06. ASTM International, hal. 460-466.

Beamish, B., McLellan, P., Endara, H., Turunc, U. dan Raab, M. (2013) "Delaying spontaneous combustion of reactive coals through inhibition," in Aziz, N. et al. (ed.) 13th Coal Operators' Conference. University of Wollongong, the Australasian Institute of Mining and Metallurgy \& Mine Managers Association of Australia, hal. 221-226.

Beamish, B. dan Beamish, R. (2010) "Benchmarking moist coal adiabatic oven testing," in Aziz, N. (ed.) 2010 Underground Coal Operators' Conference. University of Wollongong \& the Australasian Institute of Mining and Metallurgy, hal. 264-268.

Beamish, B. dan Beamish, R. (2011) “Experience with using a moist coal adiabatic oven testing method for spontaneous combustion assessment," in Aziz, N. (ed.) 11th Underground Coal Operators' Conference. University of Wollongong \& the Australasian Institute of Mining and Metallurgy, hal. 380384.

Beamish, B., Edwards, D. dan Theiler, J. (2018) "Implementation of interactive spontaneous combustion hazard assessment and management at Meandu mine," in Aziz, N. dan Kininmonth, B. (ed.) 18th Coal Operators' Conference. The University of Wollongong, hal. 329-335.

Cliff, D., Brady, D. dan Watkinson, M. (2014) "Developments in the management of spontaneous combustion in Australian underground coal mines," in Naj Aziz et al. (ed.) 2014 Coal Operators' Conference. University of Wollongong - Mining Engineering, Australasian Institute of Mining and Metallurgy and the Mine Managers Association of Australia, hal. 330-338.

Moran, M. J., Shapiro, H. N., Boettner, D. D. dan Bailey, M. B. (2018) Fundamentals of engineering thermodynamics. 9th ed. Wiley.

Nalbandian, H. (2010) Propensity of coal to selfheat. London: IEA Clean Coal Centre.

Pamungkas, S. A., Widodo, N. P., Kusuma, G. J., Prata, D. A., Sasaki, K., Sugai, Y. dan Widiatmodjo, A. (2014) "Study of spontaneous combustion characteristic using convectional air flow testing method at laboratory on Ombilin Region's coal," in International 
Symposium on Earth Science and Technology 2014. Fukuoka.

Saffari, A., Ataei, M. dan Sereshki, F. (2019) "Evaluation of the spontaneous combustion of coal (SCC) by using the R70 test method based on the correlation among intrinsic coal properties (Case study: Tabas Parvadeh coal mines, Iran)," Rudarsko-geološko-naftni zbornik, 34(3), hal. 49-60. doi: 10.17794/rgn.2019.3.6.

Sasaki, K., Wang, Y., Sugai, Y. dan Zhang, X. (2014) "Numerical modelling of low rank coal for spontaneous combustion," in Aziz, N. (ed.) 2014 Coal Operators' Conference. University of Wollongong - Mining Engineering, Australasian Institute of Mining and Metallurgy and the Mine Managers Association of Australia, hal. 344-349.

Sloss, L. L. (2015) Assessing and managing spontaneous combustion of coal. IEA Clean Coal Centre.

Wang, Y., Zhang, X., Zhang, H. dan Sasaki, K. (2019) "Effects of temperature gradient and particle size on self-ignition temperature of low-rank coal excavated from inner Mongolia, China," Royal Society Open Science, 6(9), hal. 190374. doi: 10.1098/rsos.190374.

Widodo, N. P., Sulistianto, B. dan Ihsan, A. (2018) "Analysis of explosion risk factor potential on coal reclaim tunnel facilities by modified analytical hierarchy process," International Journal of Coal Science \& Technology, 5(3), hal. 339-357. doi: 10.1007/s40789-018-0219-0.

Zhang, W., Jiang, S., Wang, K., Wang, L., Xu, Y., Wu, Z., Shao, H., Wang, Y. dan Miao, M. (2015) "Thermogravimetric dynamics and FTIR analysis on oxidation properties of lowrank coal at low and moderate temperatures," International Journal of Coal Preparation and Utilization, 35(1), hal. 39-50. doi: 10.1080/19392699.2013.873421.

Zhang, Y., Wu, J., Chang, L., Wang, J., Xue, S. dan $\mathrm{Li}, \mathrm{Z}$. (2013) "Kinetic and thermodynamic studies on the mechanism of low-temperature oxidation of coal: A case study of Shendong coal (China)," International Journal of Coal Geology, 120, hal. 41-49. doi: 10.1016/j.coal.2013.09.005 
